\title{
PARASITISM OF LEPIDOPTERAN LARVAE COLLECTED FROM VEGETABLE CROPS AND ASSOCIATED WEEDS AT PUKEKOHE
}

\author{
G.P. WALKER ${ }^{1}$, M.S. QURESHI ${ }^{1}$ and A.R. WALLACE ${ }^{2}$ \\ ${ }^{1}$ Crop \& Food Research, Private Bag 92169, Auckland \\ ${ }^{2}$ Crop \& Food Research, Private Bag 4704, Christchurch \\ Corresponding author: walkerg@crop.cri.nz
}

\begin{abstract}
A weekly survey of lepidopteran larvae present on vegetable crops and associated weeds was undertaken at Pukekohe from December 2002 to June 2003. The polyphagous pests, Thysanoplusia orichalcea (soybean looper) and Helicoverpa armigera (tomato fruitworm), were common on most species of plants, and the brassica pests, Plutella xylostella (diamondback moth) and Pieris rapae (white butterfly), were the other two species most commonly collected. The accidentally introduced polyphagous parasitoid, Meteorus pulchricornis, was reared from all lepidopteran species collected except for $P$. rapae. Results indicate that M. pulchricornis may be competitively displacing the important introduced specific parasitoid of $\mathrm{H}$. armigera, Cotesia kazak, with $89 \%$ of all parasitised $H$. armigera larvae parasitised by $M$. pulchricornis. Cotesia rubecula, an introduced solitary parasitoid of $P$. rapae, also appears to have displaced the earlier introduced Cotesia glomerata. Three species of entomopathogenic fungi were isolated from various species of Lepidoptera.
\end{abstract}

Keywords: Lepidopteran larvae, vegetables, parasitic hymenoptera, entomopathogenic fungi, Meteorus pulchricornis.

\section{INTRODUCTION}

Integrated pest management (IPM) programmes for vegetable brassicas and outdoor tomatoes have been successfully developed and implemented in New Zealand (Walker et al. 2003a, Cameron et al. 2001) and an IPM programme for lettuce is being developed (Walker et al. 2003b). The natural enemies of the main lepidopteran pests are important features of these IPM programmes. Lepidopteran pests of economic significance are the polyphagous species, Thysanoplusia orichalcea (soybean looper) and Helicoverpa armigera (tomato fruitworm), and the specialist brassica pests, Plutella xylostella (diamondback moth) and Pieris rapae (white butterfly). All of these pest species are attacked by various larval parasitoids and entomopathogenic fungi, which can affect their pest status to varying degrees. The larval parasitoids are mainly hymenopteran species that have been successfully introduced into New Zealand as biological control agents (Cameron et al. 1989). These include: Copidosoma floridanum and Cotesia ruficrus, which were introduced to control Chrysodeixis eriosoma (green looper) and which also attack T. orichalcea (Berry \& Walker 2004); Cotesia kazak and Microplitis croceipes introduced to control H. armigera (Walker \& Cameron 1989); Diadegma semiclausum introduced against $P$. xylostella; and Cotesia glomerata and Cotesia rubecula to control $P$. rapae (Cameron \& Walker 2002). The other larval parasitoid of lepidopteran larvae commonly recovered in vegetable crops is the accidentally introduced Meteorus pulchricornis, which has become an important component of the hymenopteran parasitoid fauna in modified habitats since it was first detected in 1996 (Berry \& Walker 2004). 
Naturally occurring entomopathogenic fungi have also been shown to occasionally cause high mortality of lepidopteran pest larvae in vegetable crops at Pukekohe. During late summer in the Pukekohe region, Zoophthora radicans has caused up to $75 \%$ mortality of $P$. xylostella in unsprayed cabbage crops (Walker et al. 2002) and Nomuraea rileyi caused the death of $31 \%$ of T. orichalcea and 19\% of Chrysodeixis eriosoma larvae in soybeans (Hill et al. 1987). These entomopathogens are being studied for their potential as biocontrol agents (Walter et al. 2003) and biopesticides.

A general survey of lepidopteran larvae present in a vegetable growing area at Pukekohe was made to gain more understanding of the interactions between the lepidopteran species present, their larval parasitoids and pathogens. This information will be useful in further development of IPM programmes for outdoor vegetable crops. This paper reports the results of the survey.

\section{MATERIALS AND METHODS}

Vegetable crops and associated plants and weeds growing at the Pukekohe Research Centre, South Auckland ( $174^{\circ} 55^{\prime} \mathrm{E}, 37^{\circ} 10^{\prime} \mathrm{S}$ ) were surveyed from December 2002 to June 2003. Lettuce and cabbage plantings were sampled weekly, and all lepidopteran larvae (up to a maximum of 30-50) were collected from 20 or more randomly selected plants. Larvae were also collected from adjacent turnips and a kumara crop by collecting larvae beaten from 10 or more randomly selected $0.75 \mathrm{~m}$ sections of row. Other crops were checked regularly (every 1-3 weeks) and all larvae sighted were collected to a maximum of 30-50 per species, per occasion. Larvae were also collected from weeds and other plants whenever they were sighted on these hosts during these surveys.

Larvae collected were placed individually into empty plastic tubes with a small slice of leaf from the host plant, or into tubes containing a general-purpose insect diet (GPD) (Singh 1983), and plugged with cotton. All collections were held in a laboratory at Mt Albert Research Centre, Auckland, at ambient temperature and specimens assessed within 24 hours to record the identification and instar stage of each larva. After this, collections were assessed every 2-3 days to record the fate of larvae and add fresh food material if required. Fate was determined as either: (1) unparasitised pupa or moth, (2) parasitised larva, (3) diseased larva or (4) dead of unknown cause. Parasitised larvae were maintained for cocoon formation, adult eclosion and identification. Larvae showing symptoms of infection by an entomopathogenic fungus (producing primary conidia) were sent to T. Glare (AgResearch, Lincoln) for isolation, identification and storage of the pathogen.

\section{RESULTS}

\section{Larval species}

Lepidopteran larvae were collected from eight vegetable crops (lettuce, cabbage, kumara, potato, turnip, yacon (Polymnia sonchifolia, Asteraceae), sunflower and pumpkin) and three weed species (black nightshade, Amaranthus sp. and brassica weeds). Almost half (914) of the 1883 larvae collected were $T$. orichalcea. These were most frequently collected from kumara, with weekly collections made of 30 or more larvae from late March until mid-May (316 collected during this period). This species was also common on lettuce from mid-February to early March, and again from mid-May to mid-June (234 collected from lettuce during the whole survey period for lettuce). Collections of T. orichalcea were made from all plant species except pumpkin.

Larvae of $H$. armigera were collected from all plants except pumpkin, but were only commonly found infesting crops in April, when 279 of the 303 collected were found infesting yacon, potatoes and the three weed species $(110,71$ and 98 collected respectively). Plutella xylostella and $P$. rapae were common on cabbage but not so common on turnips and brassica weeds (data not presented).

The four pest species described above, T. orichalcea, H. armigera, P. xylostella and $P$. rapae, accounted for $96 \%$ of all larvae collected (Table 1). A number of geometrid larvae were also collected, with the majority (32/55) collected from sunflower and 11 specimens beaten off turnip plants. Five larvae of two other noctuid species and six 
tortricid larvae were also reared, but are not included in Table 1 because of their low incidence.

TABLE 1: Fate of reared lepidopteran larvae as described by the percentages in four categories for each species. Larvae were collected from vegetable crops and associated weeds in Pukekohe during the 2002/03 season.

\begin{tabular}{|c|c|c|c|c|c|c|}
\hline \multirow[b]{2}{*}{ Species } & \multirow[b]{2}{*}{ Family } & \multirow[b]{2}{*}{$\begin{array}{l}\text { Total no. } \\
\text { examined }\end{array}$} & \multicolumn{4}{|c|}{ Fate $(\%)$} \\
\hline & & & $\begin{array}{l}\text { Pupae/ } \\
\text { moths }\end{array}$ & Parasitised & Diseased & $\begin{array}{c}\text { Unknown } \\
\text { death }\end{array}$ \\
\hline Thysanoplusia orichalcea & Noctuidae & 914 & 55.0 & 12.7 & 12.4 & 19.9 \\
\hline Helicoverpa armigera & Noctuidae & 303 & 25.4 & 48.8 & 5.0 & 20.8 \\
\hline Plutella xylostella & Plutellidae & 457 & 41.6 & 21.4 & 0.7 & 36.3 \\
\hline Pieris rapae & Pieridae & 143 & 22.4 & 25.9 & 0.0 & 51.7 \\
\hline Geometrid spp. & Geometridae & 55 & 58.2 & 18.2 & 3.6 & 20.0 \\
\hline $\begin{array}{l}\text { Overall total and } \\
\text { category percentages }\end{array}$ & & 1872 & 44.6 & 21.8 & 7.1 & 26.5 \\
\hline
\end{tabular}

Forty-five percent of the larvae collected were reared through to pupae and moths, with the 'success' rate ranging from less than $30 \%$ for $H$. armigera and $P$. rapae, to $40 \%$ for $P$. xylostella, to about $55 \%$ for $T$. orichalcea and geometrid species collected $(P<0.001)$. The cause of death of the remaining $55 \%$ was identified where possible (52\% of the 1043 larvae that died).

\section{Parasitism}

The most common cause of the identified deaths was parasitism, while suspected fungal and viral infections accounted for the remainder. A proportion of the larvae assessed as dead due to unknown causes were likely to be parasitised, but this was not confirmed by dissection because of time constraints. Many of the fungi and viruses that were infecting the larvae were also unable to be isolated and identified. Some deaths may have been caused by secondary infections. However, parasitism caused $40 \%$ of all identified larval deaths (412 larvae).

The incidence of parasitism varied significantly between lepidopteran species. It was highest (49\% of all larvae) in H. armigera, where M. pulchricornis was most successful. Eighty-nine per cent of all parasitised $H$. armigera larvae were parasitised by M. pulchricornis, with mortality caused by $C$. kazak and $M$. croceipes being 7 and $4 \%$ respectively. Mortality caused by parasitism ranged from 13 to $26 \%$ for the other four species (Table 1). Each of the five common lepidopteran species was host to one to three different parasitoid species. Meteorus pulchricornis was reared from three lepidopteran families (Table 2), and parasitised $43 \%$ of all collected larvae of $H$. armigera, $6 \%$ of T. orichalcea, $11 \%$ of geometrid species and $1 \%$ of P. xylostella. Meteorus pulchricornis was not reared from $P$. rapae. Other parasitoids had a relatively minor impact on their host species, with only $D$. semiclausum and $C$. rubecula killing more than $4 \%$ of the hosts collected. Diadegma semiclausum killed $20 \%$ of P. xylostella and C. rubecula killed $24 \%$ of $P$. rapae larvae collected. Three $C$. rubecula cocoons produced adults of Baryscapus galactopus, a hyperparasitoid of $P$. rapae. Geometrid larvae produced two specimens of Rogas spp., and six specimens of M. pulchricornis. Two of the geometrid larvae that were hosts for $M$. pulchricornis were identified as Bedellia psamminella collected from kumara, and an ?Asaphodes species from turnip. Four larvae of C. eriosoma collected from pumpkin produced two $M$. pulchricornis and one cocoon mass of $C$. ruficrus. Two larvae of Spodoptera litura (tropical armyworm) were collected from lettuce but were not parasitised. It is noteworthy that from 79 eggs of $T$. orichalcea and 7 of $H$. armigera also collected during this survey, no egg parasitoids were recovered. 
For three host species, $H$. armigera, $P$. xylostella and $P$. rapae, at least $89 \%$ of all parasitism was by a single parasitoid species (Table 2). However, the most common host species, T. orichalcea, was host to three parasitoid species, and, despite significant differences in incidence $(P<0.05)$, none of these was clearly dominant.

TABLE 2: Number of lepidopteran larvae of the five dominant species found in Pukekohe during the $2002 / 03$ season identified as having been killed by individual parasitoid species.

\begin{tabular}{|c|c|c|c|c|c|c|c|c|}
\hline \multirow[b]{2}{*}{ Lepidopteran species } & \multicolumn{8}{|c|}{ Parasitoid species } \\
\hline & 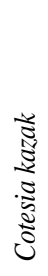 & 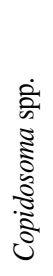 & 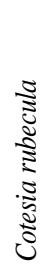 & 芯 & 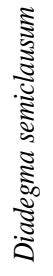 & 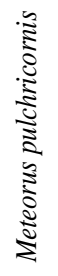 & 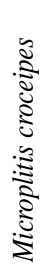 & $\begin{array}{l}\dot{2} \\
\hat{n} \\
\vdots \\
0 \\
0 \\
2\end{array}$ \\
\hline Thysanoplusia orichalcea & & 35 & & 28 & & 53 & & \\
\hline Helicoverpa armigera & 10 & & & & & 131 & 6 & \\
\hline Plutella xylostella & & & & & 93 & 5 & & \\
\hline Pieris rapae & & & 34 & & & & & \\
\hline Geometrid spp. & & & & & & 6 & & 2 \\
\hline
\end{tabular}

\section{Insect pathogens}

Identified entomopathogens caused very few lepidopteran larval deaths, less than 5\% of larvae collected, except in T. orichalcea where $12 \%$ of deaths were caused by disease (Table 1). For this species, deaths caused by parasitism and identified diseases were almost equal (116 and 113 respectively). Of the 113 T. orichalcea deaths resulting from disease, $45 \%$ were caused by fungal attack, and the remainder by virus infection (i.e. $7 \%$ of larvae collected). From all larvae collected, three species of entomopathogenic fungi were identified. Zoophthora radicans was reared from T. orichalcea, H. armigera, $P$. xylostella and a geometrid species (from 3, 5, 3 and 1 larvae respectively). Beauveria bassiana was reared from $T$. orichalcea and H. armigera (7 and 2 larvae) and an Akanthomyces sp. was identified from three T. orichalcea. However, more than half $(62 \%)$ of the deaths due to fungal infection were caused by unidentified fungi. Nomuraea rileyi, previously recorded from looper larvae from Pukekohe (Hill et al. 1987), was not recovered. Virus infection was identified, by symptoms expressed by individual larvae, as the cause of death of $62 \mathrm{~T}$. orichalcea and $8 \mathrm{H}$. armigera, but identification of viruses was not undertaken because of time and technical constraints. Subsequently, in March 2004, a small NPV (nuclear polyhedrosis virus) was identified infecting up to $17 \%$ (10 of 58) of larvae of $T$. orichalcea collected from lettuce grown in the same locality. Parasitoid-pathogen interactions

There was no significant correlation across host species $(r=0.43, \mathrm{df}=3)$ between the numbers of host larvae that died from parasitism and fungal disease. The host species with the lowest parasitism rate $(13 \%, T$. orichalcea $)$ had the highest fungal death rate (but only $5.6 \%$ of larvae collected), while the host with the highest parasitism rate (49\%, H. armigera) had an average rate of fungal death of $2.3 \%$. Thus, there is little support from this data for an increase in host larval susceptibility to fungal infection resulting from damage caused by parasitoid attack. Conversely, even in T. orichalcea the incidence of fungal and viral deaths (12\% of larvae collected) is too low to have been a significant factor in the limited parasitoid success rate (13\% of larvae collected) in this species. 


\section{DISCUSSION}

In this survey, levels of mortality caused by parasitic hymenoptera were relatively low. In previous studies at Pukekohe, mortality of $P$. xylostella caused by $D$. semiclausum reached over $70 \%$ (Walker et al. 2002), and up to $97 \%$ of $P$. rapae larvae have been parasitised by C. rubecula (Cameron \& Walker 2002). Also, in processing tomato crops, parasitism of $H$. armigera has reached $>90 \%$ (G.P. Walker, unpubl. data). The relatively low rate of parasitism in our survey was probably due to the application of broad-spectrum insecticides to some crops. The majority of the lettuce plantings were sprayed every 1-2 weeks with broad-spectrum insecticides and the cabbage crop, although unsprayed, was immediately adjacent to the lettuce plantings. The yacon and potato crops were also sprayed with broadspectrum insecticides. These sprays would have killed mobile parasitoid adults, particularly those species searching for polyphagous hosts. Our results from rearing larvae from different plant hosts confirm this observation. For example, only $6 \mathrm{~T}$. orichalcea larvae from the 190 collected from lettuce were parasitised (3\%), while 89 parasitoids were reared from 317 T. orichalcea larvae collected from unsprayed kumara, representing $77 \%$ of the parasitoids being reared from $35 \%$ of all the $T$. orichalcea larvae.

Meteorus pulchricornis is utilising a range of hosts at Pukekohe to varying degrees; it is only occasionally reared from $P$. xylostella, but parasitises a much larger proportion of available $H$. armigera larvae (Table 2). It was the dominant parasitoid species attacking $H$. armigera in this survey, being reared from $89 \%$ of all parasitised larvae. This is a very different situation to that reported by Berry \& Walker (2004) in processing tomato crops in Hawke's Bay. There, C. kazak has remained the dominant parasitoid of $H$. armigera since 1990, parasitising between 39 and $74 \%$ of all larvae every year. A comparison with Hawke's Bay in the 2002/2003 season shows that $90 \%$ of all parasitised $H$. armigera larvae collected in tomatoes from that region produced $C$. kazak, with $M$. croceipes reared from $8 \%$, and M. pulchricornis only reared from $2 \%$ of the parasitised larvae (Berry \& Walker 2004). Therefore, it appears that M. pulchricornis may be competitively displacing $C$. kazak and perhaps $M$. croceipes at Pukekohe. Laboratory studies have shown that $C$. kazak successfully attacks more small larvae and develops faster than $M$. pulchricornis, and that both these species outcompete M. croceipes for hosts (Walker \& Cameron 1989, G.P. Walker, unpubl. data). The dominance of $M$. pulchricornis in our survey may result from the availability of alternative host lepidopteran species in a multi-crop environment, so that larger populations of $M$. pulchricornis may build up in Pukekohe than in tomato crops in Hawke's Bay where M. pulchricornis has few alternative hosts (G.P. Walker, personal observation).

It is noteworthy that we only recovered $C$. rubecula from larvae of $P$. rapae, and did not recover $C$. glomerata. This is a positive example of competitive displacement because C. rubecula is the superior competitor and usually kills the host first. This parasitoid also reduces crop damage because $P$. rapae larvae that are parasitised by $C$. rubecula eat less than those parasitised by $C$. glomerata (Parker \& Pinnell 1973). C. glomerata is also recorded as having a lower attack rate than $C$. rubecula in New Zealand and a pattern of late season activity, while $C$. rubecula is better synchronised with spring and summer populations of $P$. rapae (Cameron \& Walker 2002).

During this survey, the incidence of identified entomopathogenic fungi was low. This may be due to several factors. High host populations and high humidity are important prerequisites for the occurrence of naturally occurring epizootics, and larval populations were not high this season. Also, the lettuce and potato plantings were sprayed regularly with broad-spectrum fungicides to control plant diseases. These foliar fungicides may have had negative effects on entomopathogenic fungi because, as Livingston et al. (1978) reported, the incidence of $N$. rileyi can be suppressed by fungicides in a low-density host population. In addition, the majority of collected larvae were maintained in tubes containing GPD diet. This is a labour-saving technique when rearing large numbers of lepidopteran larvae individually. However, this diet contains antibiotics that inhibit fungal growth, and would have reduced our ability to identify infection by entomopathogenic fungi. 
These results show that at Pukekohe several parasitic hymenoptera attacked all the lepidopteran pest larvae on vegetables, but the level of attack was less than that reported previously. Maximising the impact of parasitoids requires judicious use of pesticides, in particular using selective larvicides to maximise the impact of natural enemies. This use of compatible controls (selective larvicides and natural enemies) is a key component in successful IPM programmes for vegetable brassicas and process tomatoes in New Zealand, where reductions in insecticide use have been 75 and $90 \%$ respectively (Walker et al. 2002, A. Kale (Heinz-Wattie's Australasia) pers. comm.). Also, more refined sampling and rearing systems may allow isolation of more entomopathogenic fungi, that may have potential as biocontrol agents or biopesticides in developing IPM programmes for outdoor vegetables.

\section{ACKNOWLEDGEMENTS}

We thank Drs Travis Glare (AgResearch), Jo Berry (Landcare Research), Louise Malone (HortResearch) and Robert Hoare (Landcare Research) for expert identification of the entomopathogenic fungi, parasitic hymenoptera, insect viruses and Lepidoptera, respectively. Peter Workman, Peter Cameron, Frances MacDonald, Sintia Winkler and Carol Curtis assisted with field collections of larvae. Tim Herman supplied the data on parasitism of H. armigera from Hawke's Bay in 2002/03. Vegfed, the MAF Sustainable Farming Fund and the Foundation for Research, Science and Technology provided funds for this work.

\section{REFERENCES}

Berry, J.A.; Walker, G.P. 2004: Meteorus pulchricornis (Wesmael) (Hymenoptera: Braconidae: Euphorinae): an exotic polyphagous parasitoid in New Zealand. N.Z. J. Zool. 31: 33-44.

Cameron, P.J.; Hill, R.L.; Bain, J.; Thomas, W.P. (eds) 1989: A review of biological control of invertebrate pests and weeds in New Zealand 1874 to 1987. Technical communication, CAB International Institute of Biological Control 10. CAB International, Wallington, UK. $242 \mathrm{pp}$.

Cameron, P.J.; Walker, G,P.; Herman, T.J.B.; Wallace, A.R. 2001: Development of economic thresholds and monitoring systems for Helicoverpa armigera (Lepidoptera: Noctuidae) in tomatoes. J. Econ. Entomol. 94(5): 1104-1112.

Cameron, P.J.; Walker, G.P. 2002: Field evaluation of Cotesia rubecula (Hymenoptera: Braconidae), an introduced parasitoid of Pieris rapae (Lepidoptera: Pieridae) in New Zealand. Environ. Entomol. 31(2): 367-374.

Hill, M.G.; Cameron, P.J.; Dugdale, J.S.; Allan, D.J.; Walker, G.P. 1987: Biology of Thysanoplusia orichalcea (Lepidoptera: Noctuidae) in New Zealand. N.Z. Entomol. 10: 44-50.

Livingston, J.M.; Yearian, W.C.; Young, S.Y. 1978: Effect of insecticides, fungicides, and insecticide-fungicide combination on development of lepidopterous larval populations in soybean. Environ. Entomol. 7(6): 823-828.

Parker, F.C.; Pinnell, R.E. 1973: Effect on food consumption of the imported cabbageworm when parasitised by two species of Apanteles. Environ. Entomol. 2: 216-219.

Singh, P. 1983: A general-purpose insect diet mixture for rearing insects. Insect Science and its Application 4: 253-256.

Walker, G.P.; Cameron, P.J. 1989: Status of introduced larval parasitoids of tomato fruitworm. Proc. N.Z. Weed \& Pest Control Conf. 42: 229-232.

Walker, G.P.; Bush, R.; Prasad, P. 2002: Control of diamondback moth using IPM in vegetable brassica crops in New Zealand. In: Improving biocontrol of Plutella xylostella. Proc. Int. Symposium. Montpellier, France, 21-24 October 2002. CIRAD.

Walker, G.P.; Cameron, P.J.; Berry, N.A. 2003a: Implementing an IPM programme for vegetable brassicas in New Zealand. In: The management of diamondback moth and other crucifer pests: Proc. Fourth Int. Workshop. Melbourne, Australia. In press. 
Walker, G.; Workman, P.; Stufkens, M.; Wright, P.; Fletcher, J.; Qureshi, S; MacDonald, F. 2003b: Integrated pest management for outdoor lettuce. Grower, December: 21-24.

Walter, M.; Stavely, F.J.L.; Chapman, R.B.; Pell, J.K.; Glare, T.R.; Alspach, P.A.; Zydenbos, S.M. 2003: Mortality of various lepidopteran larvae infected by New Zealand Zoophthora radicans isolates from different hosts. N.Z. Plant Prot. 56: 174-179. 